\title{
Caracterização genética de mulungu (Erythrina velutina Willd.) em áreas de baixa ocorrência ${ }^{1}$
}

\author{
Genetic characterization of the coral tree (Erythrina velutina Willd.) in areas of low \\ occurrence
}

\author{
Luciana Oliveira Gonçalves² ${ }^{2}$ José Baldin Pinheiro ${ }^{3}$, Maria Imaculada Zucchi ${ }^{4}$ e Renata Silva-Mann ${ }^{5 *}$
}

\begin{abstract}
RESUMO - A Erythrina velutina Willd., popularmente conhecida como mulungu, apresenta propriedades farmacológicas e se encontra em estado de raridade em regiões do Estado de Sergipe. Devido ao interesse econômico, torna-se fundamental gerar informações para definir planos de conservação e exploração sustentável. Este trabalho teve como objetivo caracterizar os indivíduos de Erythrina velutina por meio de marcadores ISSRs. Para isto foram estudados 40 indivíduos do Estado de Sergipe pertencentes a três localidades (Município de Pinhão - Caatinga; Município de Santana do São Francisco e São Cristóvão - Mata Atlântica). Ao total, foram avaliados e obtidos 149 locos a partir de 11 primers ISSR. O número mínimo de locos para estudo de diversidade em E. velutina foi de 117 de acordo com o valor do estresse de Kruskal. Na população de Santana ocorre estruturação genética espacial e a população de Pinhão não possui estruturação genética espacial, seus indivíduos estão distribuídos de forma aleatória o que compromete a sustentabilidade ao longo do tempo, e, portanto, requer ações imediatas de conservação e recuperação.
\end{abstract}

Palavras-chave: Genética vegetal. Mulungu.

\begin{abstract}
The coral tree (Erythrina velutina Willd.), popularly known in Brazil as mulungu, presents various pharmacological properties and although extremely scarce, can be found in regions of the State of Sergipe, Brazil. Due to economic interests, producing information in order to set up plans for its conservation and sustainable exploitation becomes essential. The objective of this work was to characterize individuals of Erythrina velutina by means of ISSR markers. In order to do this, 40 individuals were studied from three locations in the State of Sergipe (The town of Pinhão - Caatinga; The towns of Santana do San Francisco and São Cristóvão - Atlantic Forest). In total, 149 loci from 11 ISSR primers were obtained and evaluated. The minimum number of loci for the study of diversity in E. velutina was 117, agreeing with Kruskal's stress value. Spatial genetic structuring is seen in the population from Santana, but the population from Pinhão lacks this structuring; its individuals are distributed randomly, compromising sustainability over time and therefore requiring immediate action for its conservation and restoration.
\end{abstract}

Key words: Genetic of Plants. Mulungu.

\footnotetext{
*Autor para correspondência

Recebido para publicação em 27/08/2012; aprovado em 25/11/2013

Trabalho extraído da Dissertação de Mestrado do primeiro autor no Programa de Pós-Graduação em Biotecnologia de Recursos Naturais financiado pelo PROCAD/CAPES

${ }^{2}$ Programa de Pós-Graduação em Biotecnologia de Recursos Naturais, Universidade Federal de Sergipe, Av. Marechal Rondon s/n Jardim Rosa Elze, São Cristóvão-SE, Brasil, 49.100-000, luoligon@gmail.com

${ }^{3}$ Departamento de Genética, Escola Superior de Agricultura "Luiz de Queiroz", Universidade de São Paulo, Av. Pádua Dias, 11, Vila Independência, Caixa Postal 83, Piracicaba-SP, Brasil, 13.400-970, baldin@ @esalq.usp.br

${ }^{4}$ Agência Paulista de Tecnologia dos Agronegócios/Polo Regional de Desenvolvimento Tecnológico do Centro Sul, Rodovia SP 127, km 30, Caixa Postal 28, Vila Fátima, Piracicaba-SP, Brasil, 13.400-970, mizucchi@gmail.com

${ }^{5}$ Departamento de Engenharia Agronômica, Universidade Federal de Sergipe, Av. Marechal Rondon s/n Jardim Rosa Elze, São Cristóvão-SE, Brasil, 49.100-000, renatamann@gmail.com
} 


\section{INTRODUÇÃO}

A fragmentação dos ecossistemas e perda da estruturação genética tem sido a principal consequência da atividade humana na exploração inadequada dos recursos naturais. Muitas das espécies que vêm sofrendo com o processo de fragmentação são fontes importantes de produtos naturais biologicamente ativos e a perda da diversidade genética implica na diminuição das chances de identificar produtos com potencial utilização econômica e a manutenção da espécie em seus hábitats. Entre essas espécies está o mulungu (Erythrina velutina Willd.), muito utilizada na medicina popular devido às propriedades medicinais. Vários trabalhos foram realizados com objetivo de isolar substâncias químicas e comprovar sua atividade terapêutica, despertando o interesse da sua utilização na produção de medicamentos (DANTAS et al., 2004; VASCONCELOS et al., 2003; VASCONCELOS et al., 2004; RIBEIRO et al., 2006). Neste sentido, o gênero Erythrina se destaca por apresentar plantas conhecidas por produzirem alcalóides, flavanóides, isoflavonóides, sendo a principal fonte de alcalóides tetracíclicos do tipo eritrina. Seus alcalóides possuem efeitos cardiovasculares e os flavanóides e isoflavanóides apresentam atividades bactericidas e antifúngicas (AMER et al.,1991; NKENGFACK et al., 2000).

As ações sedativas e bloqueadoras neuromusculares do extrato aquoso de folhas de mulungu, em altas e baixas doses, interferem em processos mnemônicos (DANTAS et al., 2004). A atividade contra Staphylococus aureus e Streptococcus pyogenes, confirmam, em alguns casos, as propriedade antibacterianas conhecidas pela medicina popular para essa espécie (VIRTUOSO et al., 2005). Estudos realizados com o mulungu têm permitido o isolamento de novos compostos, e alguns deles nunca tinham sido isolados de uma planta dessa espécie, ou até mesmo da família Fabaceae (RABELO et al., 2001), atribuindo assim novas propriedades para essa espécie. Com os estudos apresentados verifica-se um potencial biotecnológico da espécie para produção de fitoterápicos e fitofármacos.

Contudo, a espécie tem sido retirada na natureza, pela implantação de pastagens, e sua existência tem sido comprometida, o que pode levar a extinção da espécie no Estado de Sergipe.

Torna-se fundamental o estudo da caracterização genética de populações naturais, para definir estratégias de conservação e exploração racional da espécie. A forma mais utilizada para verificar a distribuição da variabilidade em populações naturais é com o uso de marcadores moleculares. A utilização dos marcadores tipo ISSR (Inter repetições de Sequências Simples) para apresentar vantagem por sua simplicidade, aplicabilidade em um grande número de espécies sem conhecimento prévio das suas sequências de DNA, por permitirem a análise de um grande número de locos e produzirem fragmentos com grande reprodutibilidade (SILVA et al., 2011).

Existem diversos estudos na literatura utilizando marcadores ISSR para análise de diversidade genética em Penstemon e plantas das famílias Asteraceae, Brassicaceae, Hippocastanaceae, Orchidaceae, Poaceae, Scrophulariaceae, Violaceae (KURANE; SHIRDE; HANSULKAN, 2009) e na espécie Tribulus terrestres (SARWAT; DAS; SRIVASTAVA, 2010). Contudo, deve-se levar em consideração a quantidade de locos necessários para se obter boa precisão das estimativas de diversidade genética. $\mathrm{O}$ uso de um grande número de marcadores pode tornar a pesquisa inviável devido ao aumento dos custos, sem levar a um aumento significativo na precisão dos dados. Em contrapartida, a utilização de um número pequeno pode comprometer a veracidade dos dados obtidos. Na literatura, dois métodos são largamente utilizados para estimar o número mínimo de fragmentos que deve ser utilizado para estimar as relações genéticas, $o$ primeiro é pelo coeficiente de variação (COELHO, 2000), e o segundo pelo estresse de Kruskal (1964).

O presente trabalho teve como objetivo estimar a diversidade genética e identificar o número mínimo de locos ISSR para avaliação de indivíduos de mulungu (Erythrina velutina).

\section{MATERIAL E MÉTODOS}

Para o estudo foram coletadas folhas jovens de 40 indivíduos em populações naturais de mulungu do Estado de Sergipe. A primeira população está localizada, no Bioma Mata Atlântica, entre os municípios de Neópolis $\left(10^{\circ} 18^{\prime} 39^{\prime \prime}\right.$ S e $36^{\circ} 34$ '56" W) e Santana do São Francisco $\left(10^{\circ} 15^{\prime} 55^{\prime \prime} \mathrm{W}\right)$ e ainda neste mesmo bioma um indivíduo da região litorânea no município de São Cristóvão $\left(10^{\circ} 55^{\prime} 32^{\prime \prime} \mathrm{S}\right.$ e $\left.37^{\circ} 06^{\prime} 08 \mathrm{~W}\right)$. A segunda população está localizada, no Bioma Caatinga, município de Pinhão ( $10^{\circ} 33^{\prime} 50^{\prime \prime} \mathrm{S}$ e $\left.37^{\circ} 42^{\prime} 47^{\prime \prime} \mathrm{W}\right)$, sendo de cada uma das populações empregados 20 indivíduos.

A extração do DNA foi realizada de acordo com método descrito por Nienhuis et al. (1995), com modificações. O DNA extraído foi quantificado utilizando gel de agarose e DNA de fago lambda (Invitrogen) de concentrações conhecidas. O DNA foi diluído à concentração de $6 \mathrm{ng} \mu \mathrm{L}^{-1}$. Foram preparados coquetéis para as reações de amplificação contendo: $20 \mathrm{ng}$ de DNA, uma unidade de Taq DNA polimerase (Invitrogen), $10 \mathrm{mM}$ de Tris-HCL ( $\mathrm{pH} 8,0$ ), $2 \mathrm{mM}$ de $\mathrm{MgCl}_{2}, 0,25 \mu \mathrm{M}$ de cada desoxirribonucleotídeo trifosfato (DNTPs) e $0,2 \mu \mathrm{M}$ de oligonucleotideos e água ultrapura para completar o 
volume de $25,0 \mu \mathrm{L}$. As reações foram realizadas usando uma etapa inicial de $94{ }^{\circ} \mathrm{C}$ por 1 minuto e 30 segundos, seguida de 35 ciclos de amplificação, de $94{ }^{\circ} \mathrm{C}$ durante 45 segundos; temperatura específica para cada primer (Tabela 1) por 45 segundos e $72{ }^{\circ} \mathrm{C}$ por 1 minuto e 30 segundos, seguido por um ciclo de extensão final de 72 ${ }^{\circ} \mathrm{C}$ durante 5 minutos. Após as reações, os produtos das amplificações foram separados por eletroforese em gel de agarose a $1,4 \%$ durante quatro horas a $120 \mathrm{~V}$, utilizando um marcador de 100 pares de bases (Invitrogen) como referência para os fragmentos gerados e corado com Blue Green Loading Dye I (LGC Biotecnologia). A visualização foi feita através de luz ultravioleta em fotodocumentador.

Tabela 1 - Primers de ISSR selecionados para a espécie Erythrina velutina Willd., suas respectivas sequências e temperaturas de anelamento

\begin{tabular}{lc}
\hline \multicolumn{1}{c}{ Sequência $\left(5^{\prime}-3^{\prime}\right)$} & Ta $\left({ }^{\circ} \mathrm{C}\right)$ \\
\hline (CAG)5 & 54 \\
$(\mathrm{GTG}) 4$ & 54 \\
$(\mathrm{CA}) 6$ AT & 45 \\
$(\mathrm{CA}) 6$ AG & 41 \\
(GT)6 AT & 45 \\
(GT)6 GG & 45 \\
(CTC)4 RC & 45 \\
(AG)8 YC & 48 \\
(CA)8GC & 48 \\
GGGC (GA)8 & 54 \\
(CAC)4 AC & 45 \\
\hline
\end{tabular}

Ta: temperatura de anelamento; $\mathrm{Y}=\mathrm{C}$ ou $\mathrm{T} ; \mathrm{R}=\mathrm{A}$ ou $\mathrm{G}$

Inicialmente foram testados 41 primers ISSR, utilizando apenas 11 indivíduos para teste de polimorfismo. Entre esses indivíduos selecionados cinco são da população de Santana do São Francisco-SE (população Santana), cinco indivíduos da população de Pinhão-SE (população Pinhão) e um indivíduo de São Cristóvão-SE, o UFS13. Para cada primer foram testadas oito temperaturas de anelamento variando entre $40-55^{\circ} \mathrm{C}$. A seleção foi feita por meio da análise do perfil eletroforético, dos produtos amplificados, gerado por cada primer.

O perfil eletroforético de cada gel foi analisado visualmente, e segundo a ausência (0) ou presença (1) do fragmento foi gerada uma matriz binária (Tabela 1).

Para determinar o número mínimo de fragmentos amplificados necessários para estudos de diversidade genética, foram obtidas as estimativas de correlação (r) de valores da matriz de similaridade e o valor de estresse (E), que indica o ajuste entre a matriz original e a matriz simulada. O número ótimo de fragmentos foi calculado por meio do software GENES (CRUZ, 2007) e considerado satisfatório para as análises quando o valor do estresse foi inferior a 0,05 (KRUSKAL, 1964) e a correlação mais próxima de 1.

A similaridade genética foi calculada por meio do coeficiente de Jaccard, utilizando o programa FreeTree (PAVLICEK; HRDA; FLEGR 1999). As similaridades obtidas foram agrupadas segundo o método UPGMA (método de média aritmética não ponderada) e construído um dendrograma utilizando o programa TreeView (PAGE, 1996). Com o objetivo de verificar a consistência de cada agrupamento, foi realizada a análise bootstrap com 2.000 repetições utilizando o programa FreeTree (PAVLICEK; HRDA; FLEGR, 1999).

Com base na matriz de similaridade genética foi calculada a análise de componentes principais (ACoP) utilizando o programa XLSTAT 2009 (ADDINSOLFT, 2009).

$\mathrm{O}$ coeficiente de coancestria genética visando a análise da relação espacial entre os genótipos de cada população foi estimado pelo coeficiente de kinship, entre os pares de indivíduos para cada uma das classes de distância (HARDY, 2003). Para as estimativas do coeficiente de kinship empregou-se o programa SPAGeDI, versão 1.2 (HARDY; VEKEMANS, 2002). Foram preestabelecidas 10 classes de distância. $\mathrm{O}$ erro padrão da média das estimativas foi obtido por reamostragem jackknife e, a partir dele, foram construídos intervalos de confiança a $95 \%$ de probabilidade do coeficiente de coancestria médio estimado para classe de distância. Para testar a ocorrência de estrutura genética espacial dentro de cada classe de distância, foram feitas 1.000 permutações. O coeficiente foi calculado pela seguinte expressão 1:

$$
F i j=\left(\frac{Q i j-Q m}{1-Q m}\right)
$$

onde: Fij = coeficiente de coancestria genética entre $\mathrm{i}$ e j; Qij = probabilidade de as amostragens aleatórias de i e j serem idênticas por ascendência; $\mathrm{Qm}=$ probabilidade média de que amostragem aleatória feita na população seja idêntica por ascendência.

\section{RESULTADOS E DISCUSSÃO}

Os indivíduos foram analisados com base em 149 locos obtidos de 11 primers ISSR. O número ótimo para obter precisão desejada nas análises de diversidade genética com a espécie em estudo foi a partir de 117 fragmentos polimórficos, quando o estresse assumiu valor de 0,048 e a correlação (r) de 0,991 (Figura 1). 
Figura 1 - Coeficiente de correlação (r) e o número de fragmentos obtidos para os indivíduos de mulungu (Erythrina velutina Willd)

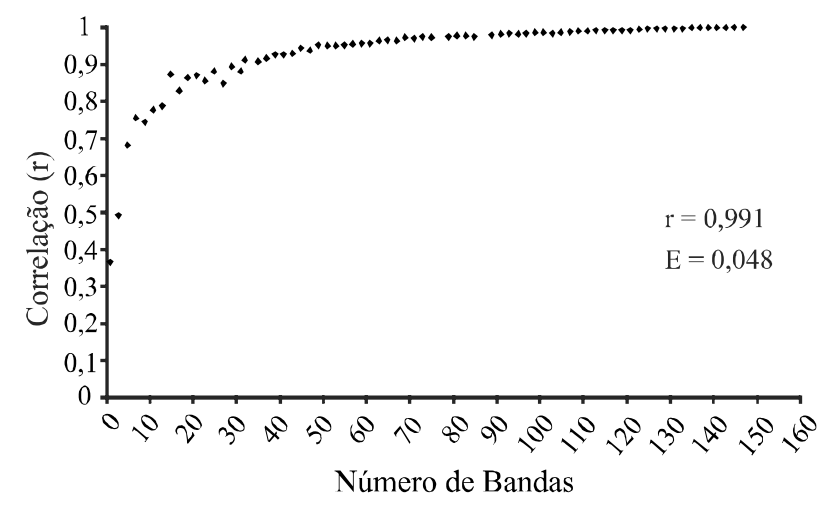

No presente estudo houve uma relação diretamente proporcional entre o número de fragmentos amplificados e a magnitude de correlação dos valores da matriz de similaridade original obtida a partir de reamostragem com diferentes números de fragmentos amplificados. Assim, a partir do número ótimo de fragmentos obtidos (117), o valor do coeficiente de correlação foi se aproximando do valor máximo, o que comprova a consistência dos dados com o número de primers utilizados e o número de fragmentos obtidos, sendo suficientes para as análises de diversidade genética.

A determinação do número de marcadores tem sido citada em espécies como soja (PEQUENO et al., 2003), em Harconia speciosa Gomez (MOURA et al., 2005) e Bidens pilosa L. (VIDAL; LAMEGO; NUNES, 2005). Nestes estudos a análise dos resultados e a indicação do número mínimo de marcadores contribui para a otimização do uso dos recursos e tempo, traduzidos em menor número de marcadores representativos da amostragem do genoma para caracterização da diversidade genética.

Em trabalho realizado com quatro espécies de Astragalus (Fabaceae), foram utilizados 15 primers ISSR, entre os 100 testados, obtendo um total de 326 locos e número de bandas variando de 13 a 26 por primer (ANAND; SRIVASTAVA; CHAUDHANY, 2010). Laxmikanta e Pratap (2010) estudando 18 espécies do gênero Cassia (Leguminosae: Caesalpinoidae), utilizaram seis primers ISSR e obtiveram um total de 115 locos. Para a espécie medicinal Carapichea ipecacuanha (Rubiaceae), foram testados 100 primers ISSR, dos quais, apenas cinco foram selecionados, produzindo um total de 89 locos, com média de 17,8 locos por primer (OLIVEIRA et al., 2010).

As relações genéticas entre os indivíduos e as populações naturais de mulungu foram estimadas utilizando dendrograma baseado no coeficiente de similaridade de Jaccard, com o método de agrupamento UPGMA e confiabilidade dos ramos avaliada por bootstraps (Figura 2).

Todos os indivíduos de mulungu tiveram identidade única. Para os pares de genótipos da população de Santana do São Francisco (Mata Atlântica) pode-se observar que a maioria apresentou similaridade genética acima de $50 \%$, destacando os pares ST9 e ST12 $(88,63 \%)$ e ST2 e ST3 $(88,46 \%)$ que obtiveram os maiores coeficientes. Os que apresentaram menor

Tabela 2 - Primers de ISSR selecionados para caracterizar indivíduos de duas populações de Erythrina velutina Willd e o número de locos gerado

\begin{tabular}{|c|c|c|}
\hline Primers & $\mathrm{N}^{\mathrm{o}}$ total de locos & $\mathrm{N}^{\mathrm{o}}$ de locos polimórficos \\
\hline$(\mathrm{CAG}) 5$ & 14 & 13 \\
\hline (GTG)4 & 19 & 19 \\
\hline (CA)6 AT & 14 & 14 \\
\hline (CA)6 AG & 15 & 15 \\
\hline (GT)6 AT & 15 & 15 \\
\hline$(\mathrm{GT}) 6 \mathrm{GG}$ & 9 & 9 \\
\hline (CTC)4 RC & 18 & 18 \\
\hline$(\mathrm{AG}) 8 \mathrm{YC}$ & 10 & 10 \\
\hline (CA)8GC & 8 & 8 \\
\hline GGGC (GA)8 & 16 & 16 \\
\hline$(\mathrm{CAC}) 4 \mathrm{AC}$ & 11 & 9 \\
\hline Total & 149 & 146 \\
\hline
\end{tabular}


Figura 2 - Dendrograma baseado no índice de similaridade de Jaccard e método de agrupamento UPGMA para os genótipos de mulungu (Erythrina velutina Willd) do município de Pinhão (PN), município de Santana de São Francisco (ST) e município de São Cristóvão (UFS). Os valores junto aos "nós" representam sua estabilidade, testada por reamostragem bootstraps, considerados significativos, aqueles superiores a $50 \%$

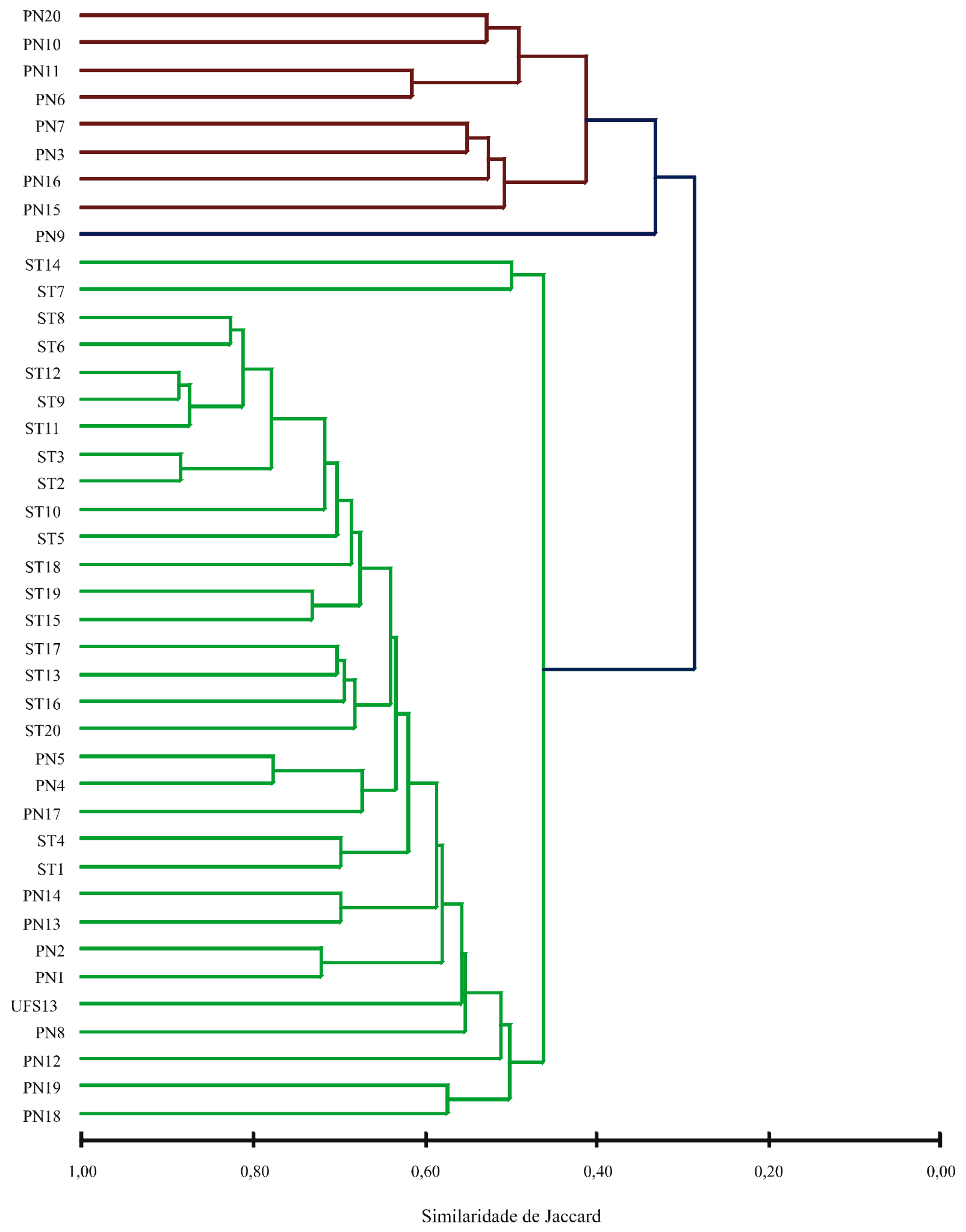


similaridade foram ST7 e ST13 com 39,79\% e ST10 e ST14 com $41,74 \%$. Vale ressaltar que os genótipos que apresentaram os menores índices de similaridade em relação aos demais foram ST7 e ST14.

Em relação à população coletada em Pinhão (P2 - Caatinga), os genótipos PN4 e PN5 (77,77\%) foram os mais similares, enquanto os PN1 e PN9 apresentaram a menor similaridade $(11,39 \%)$. Para esta população foram observados baixos índices de similaridade, predominando os valores abaixo de $50 \%$.

Com base na análise da relação de similaridade entre os genótipos das duas populações (Santana do São Francisco e Pinhão), observou-se que os ST3 e PN5 foram mais similares apresentando um índice de similaridade de $73,49 \%$. Os pares PN9 e ST20 $(14,13 \%)$ e PN9 e ST17 (14,94\%) apresentaram-se comparativamente menos similares.

O genótipo UFS13, utilizado como referência, devido à localização no campus da universidade e seu uso em ensaios farmacológicos (CARVALHO et al., 2009; SANTOS et al., 2012) mostrou-se mais semelhante aos indivíduos de Santana do São Francisco, apresentando maior similaridade com o indivíduo ST19 (63,44\%).

Analisando os 41 genótipos, pelo método de componentes principais (ACoP), houve a formação de 41 autovalores, sendo que a partir de 32 não houve incremento da variação. Para agrupar $80 \%$ da variabilidade, seriam necessários 14 autovalores. Nos três primeiros autovalores foi observada uma variabilidade acumulada de 43,33\% (Figura 3).

Utilizando os dois primeiros componentes de maior acúmulo de variação $(36,76 \%)$, há formação de dois grandes grupos, um primeiro, formado por nove indivíduos (PN3, PN6, PN7, PN9, PN10, PN11, PN15, PN16 e PN20), com maior aproximação dos indivíduos PN7, PN10 e PN15; e o segundo pelos 20 indivíduos de Santana do São Francisco, e de São Cristóvão e 11 indivíduos de Pinhão, o que sugere uma proximidade genética para estes. No entanto, ainda neste grupo, foi observado que os indivíduos ST7, ST14 e PN18 se apresentaram de maneira dispersa, indicando uma diferenciação em relação aos demais.

Para a primeira e terceira coordenada, ocorre situação semelhante. Verificou-se a formação de um agrupamento contendo os mesmos indivíduos do município de Pinhão presentes no agrupamento, mas com distribuição diferente. Em outro grupo, foi observado aproximação dos indivíduos ST14, PN18 e PN19. Nos dois gráficos de ACoP construídos, o indivíduo de São Cristóvão está associado ao agrupamento formado pela população de Santana do São Francisco.

Figura 3 - Análise de Coordenadas Principais (ACoP) para 41 indivíduos de mulungu (Erythrina velutina Willd) localizados no município de Pinhão ( $\boldsymbol{\Delta}$ ), município de Santana de São Francisco ( $\square$ ) e município de São Cristóvão (•), pertencentes ao Estado de Sergipe, para as três primeiros componentes (F1, F2 e F3). Em (A) coordenadas F1 e F2 e em (B) coordenadas F1 e F3. Agrupados em função da diversidade genética estimada pelo coeficiente de Jaccard
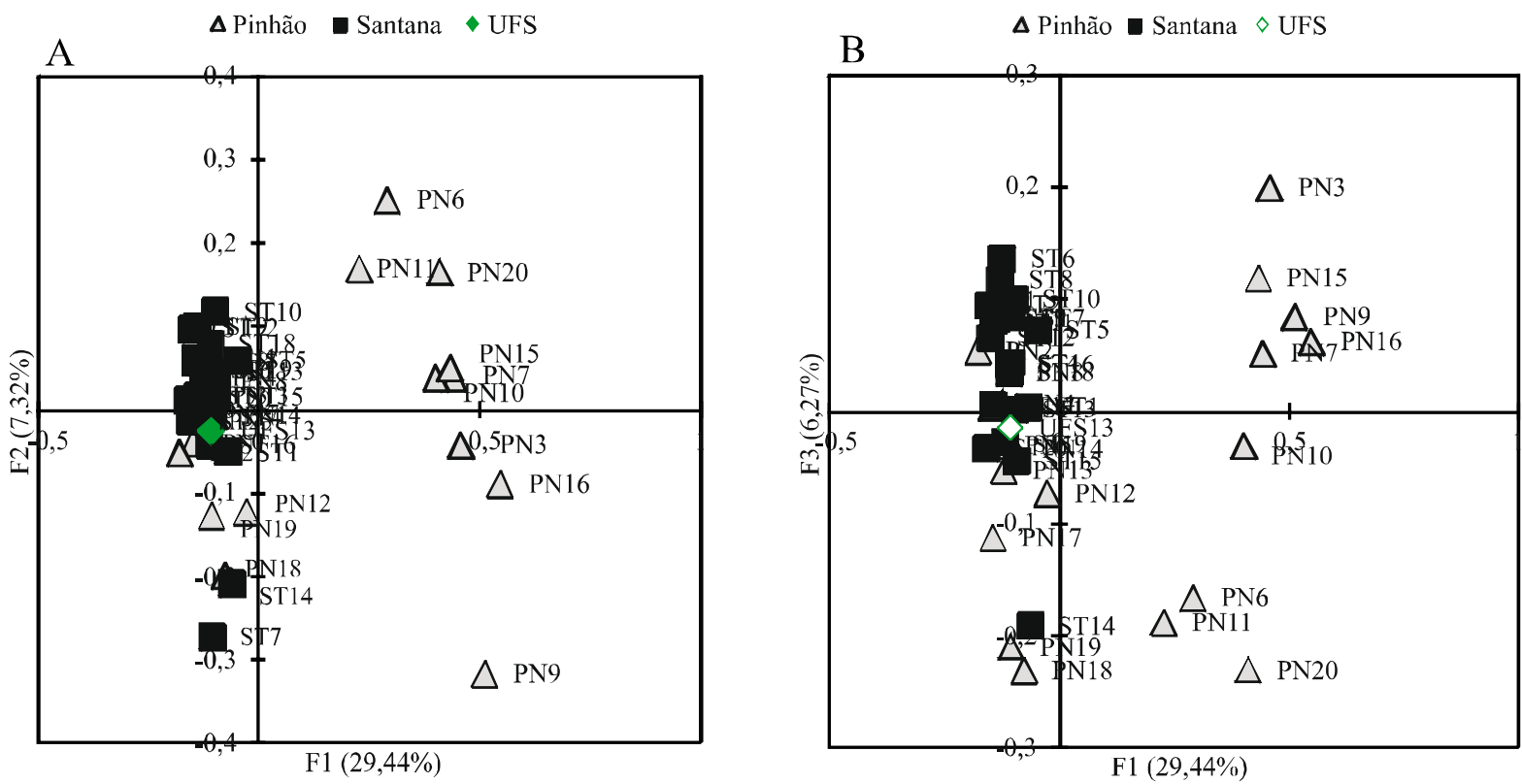
De maneira geral, os grupos formados pelo método UPGMA e ACoP apresentam concordância, confirmando a associação entre os indivíduos nos agrupamentos. O emprego de mais de um método de agrupamento, em razão das diferenças na hierarquização, otimização e ordenação dos grupos, permite que a classificação deles se complemente em função dos critérios que cada técnica utiliza, e impede que inferências errôneas sejam adotadas na alocação de materiais, dentro de um determinado subgrupo de genótipos (ARRIEL et al., 2006).

Por meio da caracterização genética dos genótipos de mulungu, foi observada a formação de dois grupos principais. O primeiro grupo formado apenas pela população de Pinhão, com destaque para o PN9 que foi o menos similar. O segundo grupo é mais diversificado, com presença de todos da população de Santana do São Francisco, Pinhão e São Cristóvão. A presença de indivíduos da população de Pinhão no segundo agrupamento indica uma alta diversidade.

Com os correlogramas a seguir tem-se a distribuição espacial dos indivíduos (Figura 4).

Figura 4 - Correlograma do coeficiente de coancestria, por classes de distâncias, para os indivíduos de Erythrina velutina Willd, nas populações de Santana e Pinhão, com intervalo de confiança a $95 \%$ de probabilidade
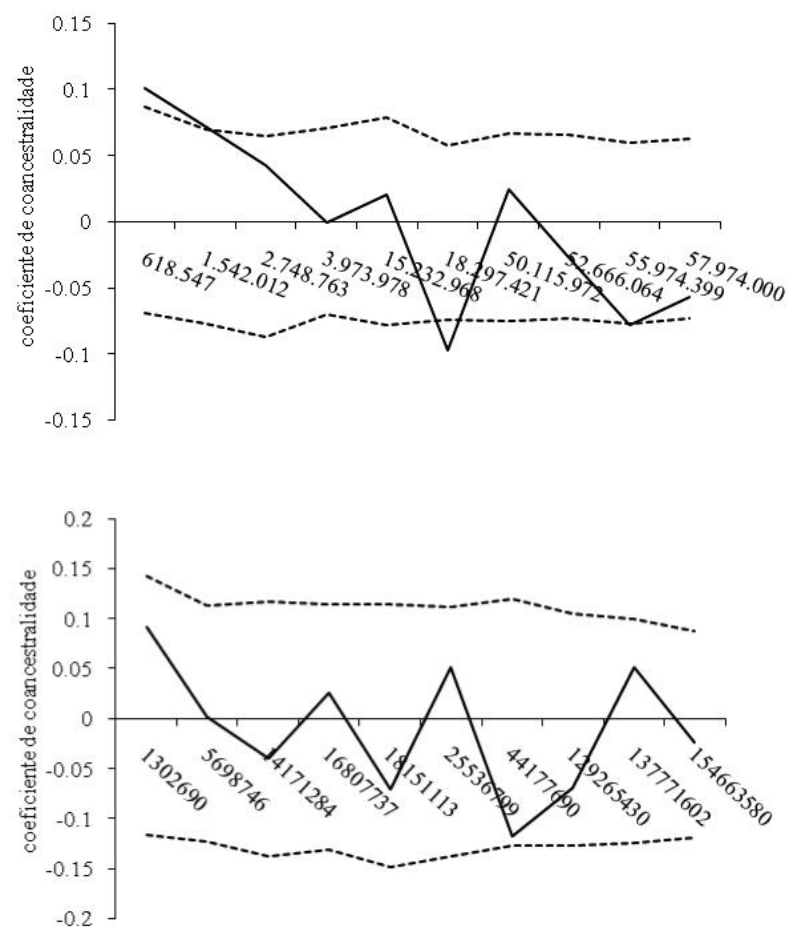

Em cada população, foram estimadas dez classes de distância espacial. De acordo com a análise, pode-se observar que o padrão de distribuição espacial variou entre as populações estudadas.

Na população de Santana do São Francisco, os pares de indivíduos da primeira e da segunda classe de distância apresentaram valores de coancestria positivos e significativos a 95\% de probabilidade (Tabela 3), sugerindo um parentesco entre eles. Esse fato, de estruturação genética espacial dentro das populações, pode estar relacionado com a dispersão limitada de pólen e sementes (SMOUSE; PEAKALL, 1999).

Na sexta e nona classes de distância, o coeficiente de coancestria apresentou-se negativo e significativo a $95 \%$ de probabilidade, indicando uma diferenciação genética entre os indivíduos, e uma possível ocorrência de estruturação genética espacial para a população de Santana do São Francisco, já que esse fato não é comprovado pelas demais classes.

Para a população de Pinhão, foi observado ocorrência de distribuição aleatória dos indivíduos, com os valores do coeficiente de coancestria oscilando entre positivo e negativo ao longo das classes, sendo não significativos a $95 \%$ de probabilidade. Por meio destes resultados pode-se inferir que indivíduos próximos geograficamente não possuem grau de parentesco. Diante disto, pode-se concluir que o grau de parentesco entre os indivíduos da população de Pinhão não é suficiente para formação de estruturação genética espacial.

O estudo da distribuição espacial nas populações de E. velutina irá contribuir para a seleção de material genético a ser utilizado nos programas de conservação e melhoramento genético da espécie e para uso em testes farmacológicos, buscando novos variantes que poderão ser pesquisados.

Diante do cenário de devastação das áreas, estudos que contemplem os genótipos prioritários para conservação são poucos. Em Sergipe, poucos trabalhos abordam o tema (SANTANA et al., 2008; GOIS; SILVA-MANN; FERREIRA, 2009; RABBANI; SILVA-MANN; FERREIRA, 2012). Estudos desse tipo, além de outros envolvendo aspectos biológicos, moleculares, econômicos, culturais e sociais tornam-se necessários tanto em nível nacional, quanto regional e local (MELO, 2007). A caracterização da diversidade genética em plantas com risco de extinção devido ao seu caráter de raridade como o mulungu em Sergipe, pode fornecer dados úteis para a identificação e seleção de genótipos em programas de conservação e também servir como referência para estudos farmacológicos. 
Tabela 3 - Valores do coeficiente de kinship (Fij) e significância (p) para as classes de distâncias nas populações de Santana do São Francisco (Mata Atlântica) e Pinhão (Caatinga) de Erythrina velutina Willd

\begin{tabular}{|c|c|c|c|c|}
\hline \multirow{3}{*}{ Classes } & \multicolumn{2}{|c|}{ População Pinhão - Caatinga } & \multicolumn{2}{|c|}{ População Santana - Mata Atlântica } \\
\hline & \multicolumn{2}{|c|}{ 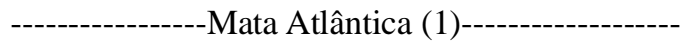 } & \multicolumn{2}{|c|}{ 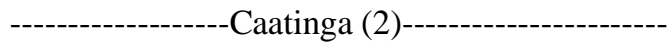 } \\
\hline & Fij & $p$ & Fij & $P$ \\
\hline 1 & 0.1012 & 0.019 & 0.0909 & 0.1429 \\
\hline 2 & 0.0713 & 0.045 & 0.0019 & 0.7802 \\
\hline 3 & 0.0423 & 0.208 & -0.0397 & 0.6943 \\
\hline 4 & -0.0005 & 0.938 & 0.0254 & 0.5784 \\
\hline 5 & 0.0206 & 0.602 & -0.0704 & 0.3007 \\
\hline 6 & -0.0974 & 0.019 & 0.0511 & 0.3127 \\
\hline 7 & 0.0248 & 0.490 & -0.1174 & 0.0709 \\
\hline 8 & -0.0265 & 0.440 & -0.0696 & 0.2468 \\
\hline 9 & -0.0779 & 0.043 & 0.0509 & 0.2807 \\
\hline 10 & -0.0574 & 0.108 & -0.0231 & 0.8082 \\
\hline
\end{tabular}

\section{CONCLUSÕES}

Este é o primeiro trabalho realizado com a espécie mulungu utilizando marcadores ISSR com populações localizadas em diferentes Biomas, sendo o número necessário de locos para estudo de diversidade genética de 117. Dentro de cada população, os genótipos ST7 e ST14 da população de Santana do São Francisco (Bioma Mata Atlântica) e PN3, PN6, PN9, PN11, PN12, PN16, PN19 e PN20 da população de Pinhão (Bioma Caatinga) são os mais divergentes, sendo esses sugeridos para trabalhos de melhoramento e programas de conservação.

\section{AGRADECIMENTOS}

Os autores agradecem à CAPES pela concessão da bolsa e suporte com o projeto PROCAD/NF 2007.

\section{REFERÊNCIAS}

ADDINSOLFT. XLSTAT for Windows. Disponível em: <http:// www.xlstat.com/>. Acesso em: 15 jan. 2009.

AMER, M.A.; SHAMMA, M.; FREYER, A.J. The tetracyclic Erythrina alkaloids. Journal of Natural Products, v. 54, n. 2, p. 329-63, 1991.

ANAND, K. K.; SRIVASTAVA, R. K.; CHAUDHARY, L. B. Analysis of Genetic Diversity in Astragalus rhizanthus Benth. ssp. rhizanthus var. rhizanthus (Fabaceae) Using Molecular Markers from India. Journal of Botany, v. 2010, p. 1-9, 2010.
ARRIEL, N. H. C.; et al. Técnicas multivariadas na determinação da diversidade genética em gergelim usando marcadores RAPD. Pesquisa Agropecuária Brasileira, v. 41, p. 801-809, 2006.

CARVALHO, A. C. C. S. et al. Evidence of the mechanism of action of Erythrina velutina Willd (Fabaceae) leaves aqueous extract. Journal of Ethnopharmacology, v. 122, n. 2, p. 374-378, 2009.

COELHO, S. G., 2000. Software DBOOT. Avaliação dos erros associados a estimativas de distâncias/similaridades genéticas através do procedimento de bootstrap com número variável de marcadores, versão 1.1. Goiânia, Brasil, Universidade Federal de Goiás.

COSTA, T. S. et al. Diversidade genética de acessos do banco de germoplasma de mangaba em Sergipe. Pesquisa Agropecuária Brasileira, v. 46, p 499-508, 2011.

CRUZ, C. D. Genes: Aplicativo computacional em genética e estatística. Viçosa, MG: UFV, 2007.

DANTAS, M. C. de. et al. Central nervous system effects of the crude extract of Erythrina velutina on rodents. Journal of Ethnopharmacology, v. 94, n. 1, p. 129-133, 2004.

GOIS, I. B.; SILVA-MANN, R.; FERREIRA, R. A. Diversidade genética de indivíduos de Spondias lutea L., por meio de isoenzimas. Scientia Forestalis, n. 37, p. 5560, 2009

HARDY O.; VEKEMANS, X. SPAGeDi: a versatile computer program to analyse spatial genetic structure at the individual or population levels. Molecular Ecology Notes, v. 2, p. 618$620,2002$.

HARDY, O. J. Estimation of pairwise relatedness between individuals and characterization of isolation-by-distance 
processes using dominant genetic markers. Molecular Ecology, v. 12, p. 1577-1588, 2003.

KRUSKAL, J. B. Multidimensional scaling by optimizing goodness of fit to a nonmetric hypothesis. Psychometrika, v. 29, n. 1 , p. $1-27,1964$.

KURANE, J.; SHINDE, V.; HARSULKAR, A. Application of ISSR marker in farmacognosy: Current update. Pharmacognosy Review, v. 3, n. 6, p. 216-228, 2009.

LAXMIKANTA, A.; PRATAP, C. P. Validation of generic status of different taxa in the sub-tribe Cassiinae (Leguminosae: Caesalpinoidae) using RAPD, ISSR and AFLP markers. International Journal of Plant Physiology and Biochemistry, v. 2, n. 2, p. 18-28, 2010.

MELO, J. G. Controle de qualidade e prioridades de conservação de plantas medicinais comercializadas no Brasil. 2007. 96 f. Dissertação (Mestrado em Botânica) - Recife: Universidade Federal Rural de Pernambuco, 2007.MOURA, N. F. et al. Seleção de marcadores RAPD para o estudo da estrutura genética de populações de Harconia speciosa Gomez. Bioscience Journal, v. 21, n. 3, p. 119-125, 2005.

NIENHUIS, J. et al. Genetic relationships among cultivars and lines of lima bean (Phaseolus lunatus L.) as measured by RAPD markers. Journal of the American Society for Horticultural Science, v. 120, n. 2, p. 300-306, 1995.

NKENGFACK A. E. et al. Indicanine A, a new 3phenylcoumarin from root bark of Erythrina indica. Journal of Natural Products, v. 63, n. 6, p. 855-856.

OLIVEIRA, L. O. O. DE. et al. Clonal diversity and conservation genetics of the medicinal plant Carapichea ipecacuanha (Rubiaceae). Genetics and Molecular Biology, v. 33 , n. 1, p. 86-93, 2010.

PAGE, R. D. M. TreeView: An application to display phylogenetic trees on personal computers. Computer Applications in the Biosciences, v. 12, n. 4, p. 357-358, 1996.

PAVLICEK, A.; HRDA, S.; FLEGR, J. FreeTree - Freeware program for construction of phylogenetic trees on the basis of distance data and bootstrap/jackknife analysis of the tree robustness. Application in the RAPD analysis of the genus Frenkelia. Folia Biologica (Praha), v. 45, n. 3, p. 97-99, 1999.

PEQUENO, S. A. et al. Determinação do número de marcadores RAPD para estudos de diversidade genética em soja utilizando o método bootstrap. Bioscience Journal, v. 19, n. 2, p. 119$125,2003$.

PINHEIRO, L. R. et al. Genetic diversity and population structure in the Brazilian Cattleya labiata (Orchidaceae) using RAPD and ISSR markers. Plant Systematics and Evolution, v. 298 , p. $1815-1825,2012$.

RABBANI, A. R. C.; SILVA-MANN, R.; FERREIRA, R. A. Variabilidade genética de Genipa americana L. pertencente ao Baixo Curso do Rio São Francisco. Revista Árvore, v. 36, n. 3, p. 401-409, 2012.
RABELO, L. A. et al. Homohesperetin and phaseollidin from Erythrina velutina. Biochemical Systematics and Ecology, v. 29, n. 5, p. 543-544, 2001.

RIBEIRO, M. D. et al. Effect of Erythrina velutina and Erythrina mulungu in rats submitted to animal models of anxiety and depression. Brazilian Journal of Medical and Biological Research, v. 39, n. 2, p. 263-270, 2006.

SANTANA, G. C. et al. Diversidade genética de indivíduos de Enterolobium contortisiliquum Vell. Morong., por meio de marcadores RAPD no Baixo Rio São Francisco. Revista Árvore, v. 32, n. 3, p. 427-433, 2008.

SANTOS, W. P. et al. In vitro and ex vivo anticholinesterase activities of Erythrina velutina leaf extracts. Pharmaceutical Biology, v. 50, n. 7, p. 919-924, 2012.

SARWAT, M.; DAS, S.; SRIVASTAVA, P. S. Estimation of genetic diversity and evaluation of relatedness through molecular markers among medicinally important trees: Terminalia arjuna, T. chebula and T. bellerica. Molecular Biology Reports, v. 38, n. 8, p. 1-12, 2010.

SILVA, K. V. P. et al. Variabilidade genética entre acessos do gênero Manihot por meio de marcadores moleculares ISSR. Pesquisa Agropecuária Brasileira, v. 46, n. 9, p. 10821088, 2011.

SILVA, A. V. C. et al. Moringa genetic diversity from germplasm bank using RAPD markers. Genetic diversity analysis of mangaba (Hancornia speciosa Gomes), an exotic brazilian tropical species. Tropical and Subtropical Agroecosystems, v. 15, n. 1, p. 217-225, 2012a.

SILVA, A. V. C. et al. Moringa genetic diversity from germplasm bank using RAPD markers. Tropical and Subtropical Agroecosystems, v. 15, n. 1, p. 31-39, 2012b.

PETER E. SMOUSE, ROD PEAKALL. Spatial autocorrelation analysis of individual multiallele and multilocus genetic structure. Heredity, v. 82, n. 5, p 561-573, 1999.

VASCONCELOS, S. M. M. et al. Central activity of hydroalcoholic extracts from Erythrina velutina and Erythrina mulungu in mice. Journal of Pharmacy and Pharmacology, v. 56, n. 3, p. 389-393, 2004.

VASCONCELOS, S. M. M. et al.. Antinociceptive activities of the hydroalcoholic extracts from Erythrina velutina and Erythrina mulungu in mice. Biological \& Pharmaceutical Bulletin, v. 26, n. 7, p. 946-949, 2003.

VIDAL, R. A.; LAMEGO, F. P.; NUNES, A. L. Otimização do número de primers empregados em RAPD para detectar variabilidade genética entre acessos de picão preto. Scientia Agraria, v. 6, n. 1/2, p. 71-77, 2005.

VIRTUOSO, S. et al. Estudo preliminar da atividade antibacteriana das cascas de Erythrina velutina Willd., Fabaceae (Leguminosae). Revista Brasileira de Farmacognosia, v. 15, n. 2, p. 137-142, 2005. 